\title{
Synthesis of Novel Cross-Linked Fluorinated Cooligomeric Nanoparticles: Synthetic Approach to Colloidal Stable Fluorinated Magnetic Nanocomposites
}

\author{
Hiroaki Yoshioka, Tamikazu Narumi and Hideo Sawada* \\ Department of Frontier Materials Chemistry, Faculty of Science and Technology, Hirosaki University (Bunkyo-cho, Hirosaki 036-8561, \\ JAPAN)
}

\begin{abstract}
Fluoroalkanoyl peroxides reacted with dimethacrylate monomer containing poly(oxyethylene) units and acrylic acid to afford cross-linked fluoroalkyl end-capped cooligomeric nanoparticles in excellent to moderate isolated yields under very mild conditions. These cross-linked fluorinated nanoparticles thus obtained were nanometer size-controlled, and these nanoparticles were found to exhibit a good dispersibility and stability in a variety of common organic solvents including water. Interestingly, these cross-linked fluorinated cooligomeric nanoparticles were applied to the preparation of colloidal stable cross-linked fluorinated cooligomeric magnetite nanoparticles.
\end{abstract}

Key words: cross-linked nanoparticle, fluorinated nanoparticle, fluorinated cooligomer, dispersibility, encapsulation, magnetite, surface modification

\section{INTRODUCTION}

Partially fluorinated polymers, especially fluoroalkyl end-capped oligomers are attractive fluorinated functional materials, because they exhibit various unique characteristic such as high solubility, surface active properties, biological activities, and nanometer size-controlled selfassembled molecular aggregates which cannot be achieved by the corresponding non-fluorinated, randomly or blocktype fluoroalkylated polymers, and low-molecular weight fluorinated surfactants ${ }^{1-11}$. The self-assembled fluorinated molecular aggregates formed by fluoroalkyl end-capped oligomers could interact with fullerene and carbon nanotube as guest molecules in aqueous media to afford fluorinated molecular aggregates-fullerene and carbon nanotube nanocomposites, respectively in aqueous solutions ${ }^{12-15)}$. However, the shape of these fluorinated molecular aggregates is in general easily exchangeable under a variety of conditions, and the encapsulated guest molecules should have an easy releasing characteristic from the aggregates cores to their outsides under these conditions ${ }^{16)}$. Therefore, it is in particular interest to develop new fluoroalkyl endcapped oligomeric nanoparticles in which their structures are fixed from the developmental viewpoints of new fluorinated functional materials. In our comprehensive studies on the chemistry of fluoroalkanoyl peroxides ${ }^{17-18}$, we have found that fluoroalkanoyl peroxides could react with dimethacrylate monomer containing poly(oxyethylene) units and acrylic acid to afford cross-linked fluoroalkyl end-capped cooligomeric nanoparticles without the formation of gels and cross-linked polymeric products with no solubility. In addition, these new cross-linked fluorinated nanoparticles were applicable to the preparation of $\mathrm{col}^{-}$ loidal stable fluorinated magnetic nanoparticles in a variety of solvents. To the best of our knowledge, our finding is the first example of the preparation of cross-linked fluorinated oligomeric nanoparticles. These results will be described herein.

\footnotetext{
* Correspondence to: Hideo Sawada, Department of Frontier Materials Chemistry, Faculty of Science and Technology, Hirosaki University, Bunkyo-cho, Hirosaki 036-8561, JAPAN

E-mail: hideosaw@cc.hirosaki-u.ac.jp

Accepted March 9, 2007 (received for review January 11, 2007)
}

Journal of Oleo Science ISSN 1345-8957 print / ISSN 1347-3352 online

http://jos.jstage.jst.go.jp/en/ 


\section{H. Yoshioka, T. Narumi and H. Sawada}

\section{EXPERIMENTAL}

2.1 Synthesis of cross-linked fluoroalkyl end-capped cooligomeric nanoparticles

Perfluoro-2-methyl-3-oxaheptanoyl peroxide (5.4 mmol) in $1: 1$ mixed solvents (AK-225) of 1,1-dichloro-2,2,3,3,3pentafluoropropane and 1,3-dichloro-1,2,2,3,3-pentafluoropropane $(250 \mathrm{~g})$ was added to a mixture of dimethacrylate monomer containing poly(oxyethylene) units (PDE-100) (6.2 $\mathrm{mmol})$ and acrylic acid $(56.7 \mathrm{mmol})$. The solution was stirred at $45^{\circ} \mathrm{C}$ for $5 \mathrm{~h}$ under nitrogen, and then was centrifuged for $30 \mathrm{~min}$. The expected fluorinated nanoparticles were easily separated from this solution. Fluorinated nanoparticle powders thus obtained were dried in vacuo at $50^{\circ} \mathrm{C}$ for 2 day to afford particle powders. The fluorinated nanoparticle powders were added to fresh methanol, and were stirred with magnetic stirring bar at room temperature for 2 days to give fluorinated fine colloidal nanoparticles, and then were dried at $50^{\circ} \mathrm{C}$ for 2 days to afford the purified cross-linked nanoparticles $\left[\mathrm{R}_{\mathrm{F}}-(\mathrm{PDE}-100)_{\mathrm{x}}-(\mathrm{ACA})_{\mathrm{y}}{ }^{-}\right.$ $\left.\mathrm{R}_{\mathrm{F}}: \mathrm{R}_{\mathrm{F}}=\mathrm{CF}\left(\mathrm{CF}_{3}\right) \mathrm{OC}_{3} \mathrm{~F}_{7}:(2.76 \mathrm{~g})\right]$. Other cross-linked fluoroalkyl end-capped cooligomeric nanoparticles were prepared under similar conditions.

\subsection{Preparation of cross-linked fluoroalkyl end-capped cooligomeric magnetic nanoparticles}

To an aqueous solution containing $\mathrm{FeCl}_{2} 4 \mathrm{H}_{2} \mathrm{O}(1.5 \mathrm{mmol})$ and $\mathrm{FeCl}_{3} 6 \mathrm{H}_{2} \mathrm{O}(2.7 \mathrm{mmol})$ was added an aqueous solution $(10 \mathrm{ml})$ containing $\mathrm{R}_{\mathrm{F}}-(\mathrm{PDE}-100)_{\mathrm{x}}-(\mathrm{ACA})_{\mathrm{y}}-\mathrm{R}_{\mathrm{F}}: \mathrm{R}_{\mathrm{F}}=$ $\mathrm{CF}\left(\mathrm{CF}_{3}\right) \mathrm{OC}_{3} \mathrm{~F}_{7}:\left(4 \mathrm{~g} / \mathrm{dm}^{3}\right)$. The mixture was sonicated for 30 min at room temperature, and was then made alkaline $\mathrm{pH}$ 10) by the addition of $25 \%$ ammonia aqueous solution. The product was recovered by a permanent magnet and then washed with water to remove free fluorinated cross-linked nanoparticles $\left[\mathrm{R}_{\mathrm{F}}-(\mathrm{PDE}-100)_{\mathrm{x}}-(\mathrm{ACA})_{\mathrm{y}}-\mathrm{R}_{\mathrm{F}}\right]$. The obtained black material was dried into powder at $50^{\circ} \mathrm{C}$ in vacuo to afford $\mathrm{R}_{\mathrm{F}}-(\mathrm{PDE}-100)_{\mathrm{x}}-(\mathrm{ACA})_{\mathrm{y}}-\mathrm{R}_{\mathrm{F}}$ - encapsulated magnetite particles $(308 \mathrm{mg})$. XRD analyses of the obtained product showed the presence of magnetite (data not shown).

\subsection{Surface modification of poly (methyl methacrylate)}

[PMMA]

The PMMA film was prepared by casting the mixture of tetrahydrofuran solution (40 ml) containing PMMA (1.0 g) and $\mathrm{R}_{\mathrm{F}}-(\mathrm{PDE}-100)_{\mathrm{x}}-(\mathrm{ACA})_{\mathrm{y}}-\mathrm{R}_{\mathrm{F}}-$ encapsulated magnetite particles $(30 \mathrm{mg}$ ) on a glass plate. The solvent was evaporated at room temperature, and the film formed peeled off and dried at $50^{\circ} \mathrm{C}$ for $24 \mathrm{hr}$ under vacuum.

\section{RESULTS AND DISCUSSION}

The reactions of fluoroalkanoyl peroxides with dimethacrylate monomer (PDE-100) with acrylic acid (ACA) were carried out in $1: 1$ mixed solvents (AK-225) of 1,1-dichloro-2,2,3,3,3-pentafluoropropane and 1,3-dichloro1,2,2,3,3-pentafluoropropane at $45^{\circ} \mathrm{C}$ for $5 \mathrm{hr}$ under nitrogen. The process is outlined in Scheme 1.

As shown in Scheme 1, fluoroalkanoyl peroxides reacted with PDE-100 and ACA under very mild conditions to afford the corresponding cross-linked fluoroalkyl endcapped cooligomeric particles in $30 \sim 61 \%$ isolated yields. The results for these reactions were summarized in Table 1.

As shown in Table 1, the higher product yields were obtained in the cross-linked longer fluoroalkyl end-capped cooligomeric particles. In particular interest, our present cross-linked fluroalkyl end-capped cooligomeric particles thus obtained were found to exhibit a good dispersibility and stability in not only water but also in common organic solvents such as methanol, ethanol, tetrahydrofuran, chloroform, benzene, toluene, ethyl acetate, dimethyl sulfoxide, dimethylformamide, acetone, and 1,2-dichloroethane including fluorinated aliphatic solvents (AK-225).

We have measured the size of cross-linked fluorinated cooligomeric particles in AK-225 and water by dynamic light scattering (DLS) measurements (DLS-6000 HL: Otsuka Electronics Co., Ltd., Japan) at $30^{\circ} \mathrm{C}$. These results were also shown in Table 1.

As shown in Table 1, our present cross-linked fluorinated cooligomeric particles were nanometer size-controlled
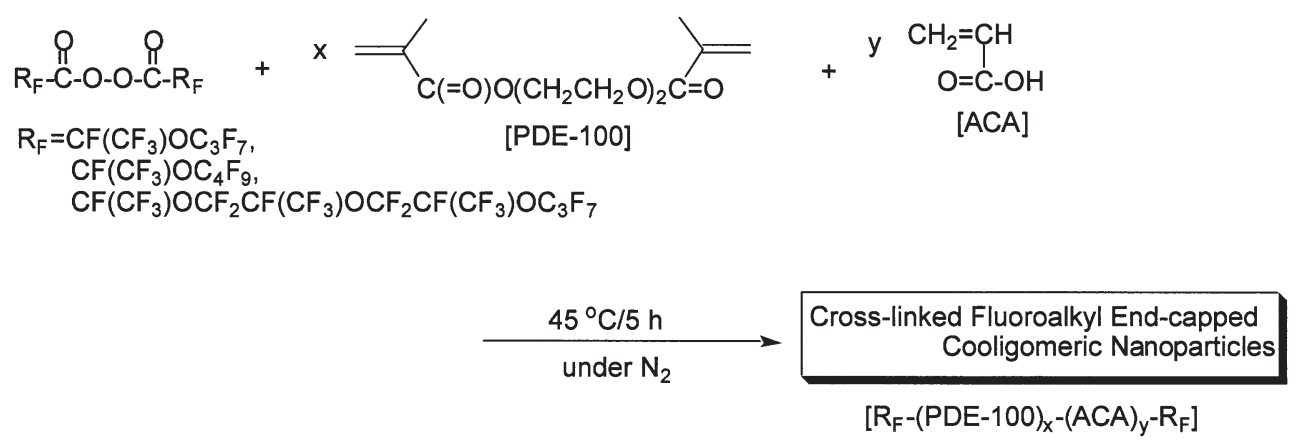

Scheme 1 
Table 1 Preparation of $\mathrm{R}_{\mathrm{F}}-(\mathrm{PDE}-100)_{\mathrm{x}}-(\mathrm{ACA})_{\mathrm{y}}-\mathrm{R}_{\mathrm{F}}$.

\begin{tabular}{|c|c|c|c|c|c|c|}
\hline Run & $\begin{array}{l}\mathrm{R}_{\mathrm{F}} \text { in Peroxide } \\
(\mathrm{mmol})\end{array}$ & $\begin{array}{l}\text { PDE-100 } \\
(\mathrm{mmol})\end{array}$ & $\begin{array}{l}\text { ACA } \\
(\mathrm{mmol})\end{array}$ & $\begin{array}{l}\text { Yield }^{a)} \\
(\%)\end{array}$ & $\begin{array}{l}\text { Size of Dispersed } \\
\text { Particles }(\mathrm{nm})\end{array}$ & $\begin{array}{l}\text { Size of Redispersed } \\
\text { Particles (nm) }\end{array}$ \\
\hline & \multicolumn{6}{|c|}{$\mathrm{R}_{\mathrm{F}}=\mathrm{CF}\left(\mathrm{CF}_{3}\right) \mathrm{OC}_{3} \mathrm{~F}_{7}$} \\
\hline \multirow[t]{2}{*}{1} & 5.4 & 6.2 & 56.7 & 30 & $40.5 \pm 2.5^{b)}$ & $42.1 \pm 10.5^{b)}$ \\
\hline & \multicolumn{6}{|c|}{$\mathrm{R}_{\mathrm{F}}=\mathrm{CF}\left(\mathrm{CF}_{3}\right) \mathrm{OC}_{4} \mathrm{~F}_{9}$} \\
\hline 2 & 6.1 & 4.8 & 50.0 & 49 & $208.5 \pm 51.7^{b)}$ & $204.2 \pm 39.2^{b)}$ \\
\hline 3 & 4.9 & 23.6 & 5.1 & 55 & $363.1 \pm 55.9^{\mathrm{c})}$ & $403.3 \pm 47.1^{c)}$ \\
\hline & \multicolumn{6}{|c|}{$\mathrm{R}_{\mathrm{F}}=\mathrm{CF}\left(\mathrm{CF}_{3}\right) \mathrm{OCF}_{2} \mathrm{CF}\left(\mathrm{CF}_{3}\right) \mathrm{OCF}_{2} \mathrm{CF}\left(\mathrm{CF}_{3}\right) \mathrm{OC}_{3} \mathrm{~F}_{7}$} \\
\hline 4 & 5.38 & 23.4 & 5.0 & 61 & $281.4 \pm 33.2^{\mathrm{c})}$ & $311.1 \pm 61.9^{c)}$ \\
\hline
\end{tabular}

a) The yield is based on the decarboxylated peroxide unit $\left(R_{F}-R_{F}\right)$ units and comonomers.

b) Particle size was determined in AK-225 by DLS measurements.

c) Particle size was determined in water by DLS measurements.

(41 $363 \mathrm{~nm}$ : number-average diameter). Interestingly, isolated fluorinated nanoparticle powders in Table 1 were found to exhibit a superior redispersibility and stability in AK-225 and water. The size $(42 \sim 403 \mathrm{~nm})$ of the redispersed fluorinated particles did not change even after the redispersion of the parent fluorinated particle powders into AK-225 and water (Table 1), and the size of each particle showed a monodispersed characteristic. This finding would be due to the electronic repulsion between fluoroalkyl segments in cross-linked fluorinated nanoparticles.

We have measured SEM (scanning electron microscopy) photographs of AK-225 solution of $\mathrm{R}_{\mathrm{F}}-(\mathrm{PDE}-100)_{\mathrm{x}}-(\mathrm{ACA})_{\mathrm{y}}-\mathrm{R}_{\mathrm{F}}$ [Run 1 in Table $1 ; \mathrm{R}_{\mathrm{F}}=\mathrm{CF}\left(\mathrm{CF}_{3}\right) \mathrm{OC}_{3} \mathrm{~F}_{7}$ ], and the result was shown in Fig. 1.

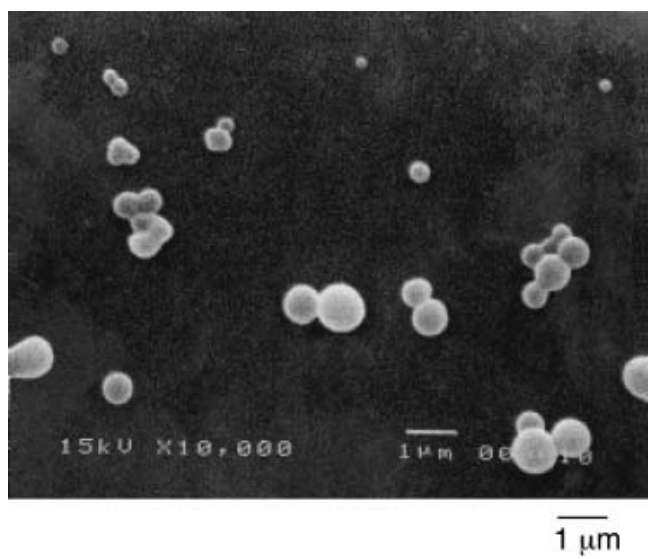

Fig. 1 SEM(scanning electron microscopy) Images of AK-225 Solutions of $\mathrm{R}_{\mathrm{F}^{-}}$ $(\mathrm{PDE}-100)_{\mathrm{x}}-(\mathrm{ACA})_{\mathrm{y}}-\mathrm{R}_{\mathrm{F}}$ (Run 1 in Table 1).
The electron micrograph also shows the formation of very fine fluorinated nanoparticles with a mean diameter of $519 \mathrm{~nm}$. The difference in the average sizes determined by DLS and SEM (DLS: $42 \mathrm{~nm}$ and SEM: $\sim 519 \mathrm{~nm}$ ) would be due to the coagulation or agglomeration of the nanoparticles during sample preparation for SEM measurements.

We have tested the AK-225 and aqueous solutions containing cross-linked fluorinated cooligomeric nanoparticles for the dispersibility and stability by the use of UV-vis. spectra at $30^{\circ} \mathrm{C}$ (Fig. 2).

Figure 2 shows the UV-vis spectra changes of the absorbance at $\lambda=500 \mathrm{~nm}$ of AK-225 and aqueous solutions containing cross-linked fluorinated cooligomeric colloidal particles as a function of time. As shown in Fig. 2, it was clarified that our present cross-linked fluorinated cooligomeric colloidal particles are well-dispersed in AK$225[(\mathrm{~A})$ and $(\mathrm{B})]$ and water $[(\mathrm{C})]$ with a good stability. Espe-

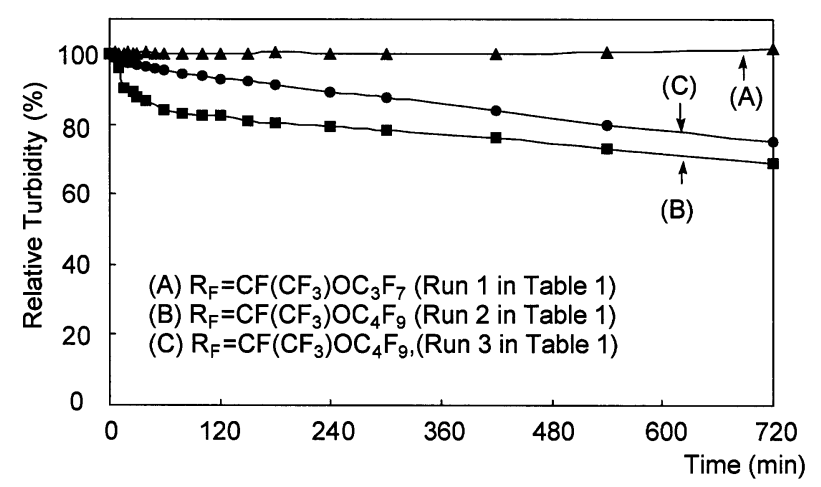

Fig. 2 Relative Turbidity at Absorbance : $\lambda=500 \mathrm{~nm}$ of AK-225 and Aqueous Solutions Containing $\mathrm{R}_{\mathrm{F}}$ $(\mathrm{PDE}-100)_{\mathrm{x}}-(\mathrm{ACA})_{\mathrm{y}}-\mathrm{R}_{\mathrm{F}}\left(2 \mathrm{~g} / \mathrm{dm}^{3}\right)$ Depending on the Time. 


\section{H. Yoshioka, T. Narumi and H. Sawada}

cially, the highest colloidal stability was obtained in the case of $\mathrm{R}_{\mathrm{F}}-(\mathrm{PDE}-100)_{\mathrm{x}}-(\mathrm{ACA})_{\mathrm{y}}-\mathrm{R}_{\mathrm{F}}$ [Run 1 in Table $1 ; \mathrm{R}_{\mathrm{F}}=$ $\mathrm{CF}\left(\mathrm{CF}_{3}\right) \mathrm{OC}_{3} \mathrm{~F}_{7}$ ], and this nanoparticle has been found to be stable for more than 3 months at room temperature.

It is of particular interest to apply our present crosslinked fluorinated nanoparticles possessing a good dispersibility and stability to the surface modification for common polymeric materials such as poly(methyl methacrylate). Thus, $\mathrm{R}_{\mathrm{F}}-(\mathrm{PDE}-100)_{\mathrm{x}}-(\mathrm{ACA})_{\mathrm{y}}-\mathrm{R}_{\mathrm{F}}$ (Run 1 in Table 1) was tested for the surface activity as a new type of surface modification agent. We have prepared the cast PMMA film (film thickness: $241 \mu \mathrm{m}$ ) treated with the fluorinated nanoparticles, and the contact angle of dodecane on the modified PMMA film surface showed a significantly large value $\left(41^{\circ}\right)$, which exhibits a good oleophobicity imparted by fluoroalkyl segments in nanoparticles on the PMMA surface. In contrast, the contact angles of dodecane on the reverse side were $0^{\circ}$ in this film, indicating that our present fluorinated nanoparticles can be dispersed regularly above the polymer surface during the cast film formation.

Hitherto, there has been a great interest in magnetite nanoparticles for high-density data storage, ferrofluids, magnetic resonance imaging, bioseparation, and probe materials in biology ${ }^{19)}$. From the developmental viewpoints of magnetic nanoparticles into a wide variety of fields, it is very important to prepare the stable colloidal dispersion of magnetite nanoparticles through the coating and encapsulation of the particles with organic polymers ${ }^{20-27)}$. Therefore, it is of particular interest to prepare the colloidal stable magnetite nanoparticles by the use of our present cross-linked fluorinated cooligomeric nanoparticles. In fact, we have prepared $R_{F}-(P D E-100)_{x}-(A C A)_{y}-R_{F}-$ encapsulated magnetite nanocomposites by the coprecipitation of $\mathrm{Fe}^{2+}$ and $\mathrm{Fe}^{3+}$ salts in the presence of $\mathrm{R}_{\mathrm{F}}-(\mathrm{PDE}-100)_{\mathrm{x}}{ }^{-}$ $(A C A)_{y^{-}} R_{F}$ (Run 1 in Table 1 ) in aqueous and tetrahydrofuran solutions under alkaline conditions. Similarly, $\mathrm{R}_{\mathrm{F}^{-}}$ $(\mathrm{PDE}-100)_{\mathrm{x}}-(\mathrm{ACA})_{\mathrm{y}}-\mathrm{R}_{\mathrm{F}}$-encapsulated magnetite nanocomposites were also prepared by the addition of magnetite nanoparticles $(10 \mathrm{~nm})$ in this coprecipitation. These results were shown in Scheme 2 and Table 2.

As shown in Scheme 2 and Table 2, $\mathrm{R}_{\mathrm{F}}-(\mathrm{PDE}-100)_{\mathrm{x}}{ }^{-}$ (ACA) $)_{\mathrm{y}}-\mathrm{R}_{\mathrm{F}}$-encapsulated magnetite nanocomposites were obtained in $86 \sim 93 \%$ isolated yields. The size (19 nm: number-average diameter) of parent cross-linked fluorinated cooligomeric nanoparticles $\left[\mathrm{R}_{\mathrm{F}}-(\mathrm{PDE}-100)_{\mathrm{x}}-(\mathrm{ACA})_{\mathrm{y}}-\mathrm{R}_{\mathrm{F}}\right]$ was increased by the magnetization of a $\mathrm{Fe}^{2+}$ and $\mathrm{Fe}^{3+}$ salts in the presence of $\mathrm{R}_{\mathrm{F}}-(\mathrm{PDE}-100)_{\mathrm{x}}-(\mathrm{ACA})_{\mathrm{y}}-\mathrm{R}_{\mathrm{F}}$ under

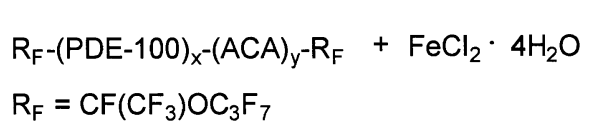

(THF: tetrahydrofuran)

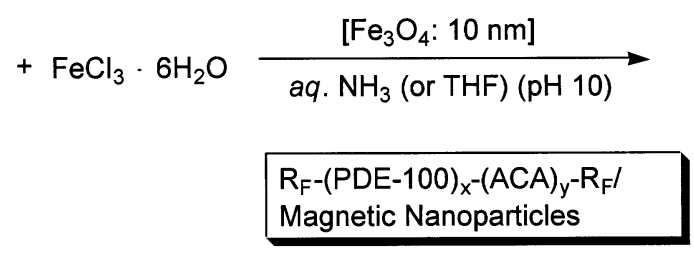

Scheme 2

Table 2 Preparation of $\mathrm{R}_{\mathrm{F}}-(\mathrm{PDE}-100)_{\mathrm{x}}-(\mathrm{ACA})_{\mathrm{y}}-\mathrm{R}_{\mathrm{F}}-$ Magnetic Nanoparticles in Aqueous and Tetrahydorofuran (THF) Solutions $\left[\mathrm{R}_{\mathrm{F}}=\mathrm{CF}\left(\mathrm{CF}_{3}\right) \mathrm{OC}_{3} \mathrm{~F}_{7}\right]$.

\begin{tabular}{ccccccc}
\hline Run $\begin{array}{l}\mathrm{R}_{\mathrm{F}}-(\mathrm{PDE}-100)_{\mathrm{x}}-(\mathrm{ACA})_{\mathrm{y}}-\mathrm{R}_{\mathrm{F}} \\
(\mathrm{mg})\end{array}$ & $\begin{array}{l}\mathrm{FeCl}_{2} \cdot 4 \mathrm{H}_{2} \mathrm{O} \\
(\mathrm{mmol})\end{array}$ & $\begin{array}{l}\mathrm{FeCl}_{3} \cdot 6 \mathrm{H}_{2} \mathrm{O} \\
(\mathrm{mmol})\end{array}$ & $\begin{array}{l}\mathrm{Fe}_{3} \mathrm{O}_{4}(10 \mathrm{~nm}) \\
(\mathrm{mg})\end{array}$ & $\begin{array}{l}\mathrm{Yield}^{\mathrm{a})} \\
(\%)\end{array}$ & $\begin{array}{l}\mathrm{Particle} \mathrm{Size}^{\mathrm{b})} \\
(\mathrm{nm})\end{array}$ \\
\hline \multicolumn{2}{l}{ aqueous solution } \\
1
\end{tabular}

a) Yield was based on $\mathrm{R}_{\mathrm{F}}-(\mathrm{PDE}-100)_{\mathrm{x}}-(\mathrm{ACA})_{\mathrm{y}}-\mathrm{R}_{\mathrm{F}}$, and $\mathrm{Fe}_{3} \mathrm{O}_{4}$ derived from the magnetization of $\mathrm{FeCl}_{2}$ and $\mathrm{FeCl}_{3}$ under alkaline conditions (and used $\mathrm{Fe}_{3} \mathrm{O}_{4}$ ).

b) Particle size determined by dynamic light scattering measurements in THF.

c) Particle size of parent $R_{F}-(P D E-100)_{x}-(A C A)_{y}-R_{F}$ in THF. 
alkaline conditions from $19 \mathrm{~nm}$ to $57 \mathrm{~nm}$. The increase of the size of nanoparticles indicates that the magnetization of iron chlorides in the presence of $\mathrm{R}_{\mathrm{F}}-(\mathrm{PDE}-100)_{\mathrm{x}}-(\mathrm{ACA})_{\mathrm{y}}{ }^{-}$ $\mathrm{R}_{\mathrm{F}}$ could proceed under alkaline conditions to afford fine fluorinated magnetic nanoparticles with around $50 \mathrm{~nm}$ size levels. This magnetization with iron chlorides could also proceed smoothly in the presence of magnetite nanoparticles $(10 \mathrm{~nm})$ to afford $\mathrm{R}_{\mathrm{F}}-(\mathrm{PDE}-100)_{\mathrm{x}}-(\mathrm{ACA})_{\mathrm{y}}-\mathrm{R}_{\mathrm{F}}$-encapsulated magnetite nanoparticles. Especially, $\mathrm{R}_{\mathrm{F}}-(\mathrm{PDE}-100)_{\mathrm{x}}{ }^{-}$ $(\mathrm{ACA})_{\mathrm{y}}-\mathrm{R}_{\mathrm{F}}$ should be incorporated homogeneously into the magnetic nanoparticles including the coprecipitates of iron chlorides under alkaline conditions, utilizing covalently binding the carboxyl groups in fluorinated cooligomeric nanoparticles onto the residual hydroxyl groups in magnetic particles. In fact, Liao et al. have been already reported that a magnetic nano-adsorbent has been developed by the covalently binding of polyacrylic acid on magnetic nanoparticles ${ }^{28}$.

We have measured TEM (transmission electron microscopy) photographs of tetrahydrofuran solution of $\mathrm{R}_{\mathrm{F}}$ (PDE-100) $)_{\mathrm{x}}-(\mathrm{ACA})_{\mathrm{y}}-\mathrm{R}_{\mathrm{F}}$-magnetite nanocomposites (Run 4 in Table 2), and the result was shown in Fig. 3.

The electron micrograph also shows the formation of very fine fluorinated magnetic nanoparticles with a mean diameter of $22 \mathrm{~nm}$.

The contents of $R_{\mathrm{F}}-(\mathrm{PDE}-100)_{\mathrm{x}}-(\mathrm{ACA})_{\mathrm{y}}-\mathrm{R}_{\mathrm{F}}$ in the magnetite nanocomposites illustrated in Table 2 were estimated by the use of TGA (thermogravimetric analyses), and the results were shown in Fig. 4.

As shown in Fig. 4, the thermal stability of parent $\mathrm{R}_{\mathrm{F}^{-}}$ $(\mathrm{PDE}-100)_{\mathrm{x}}-(\mathrm{ACA})_{\mathrm{y}}-\mathrm{R}_{\mathrm{F}}$ was found to decrease extremely compared to that of the fluorinated magnetite nanocomposites or the original magnetite nanoparticles $(10 \mathrm{~nm})$. This finding is due to the presence of magnetite in the composites. The contents of $\mathrm{R}_{\mathrm{F}}-(\mathrm{PDE}-100)_{\mathrm{x}}-(\mathrm{ACA})_{\mathrm{y}}-\mathrm{R}_{\mathrm{F}}$ in the composites were estimated to be $23 \sim 50 \%$ by the use

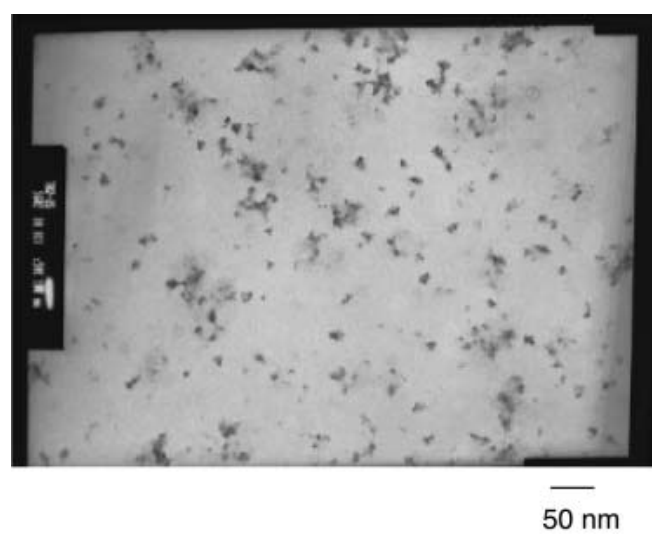

Fig. 3 TEM Images of $\mathrm{R}_{\mathrm{F}}-(\mathrm{PDE})_{\mathrm{x}}-(\mathrm{ACA})_{\mathrm{y}^{-}}$ $\mathrm{R}_{\mathrm{F}}$-Magnetic Nanoparticles [Run 4 in Table 2].

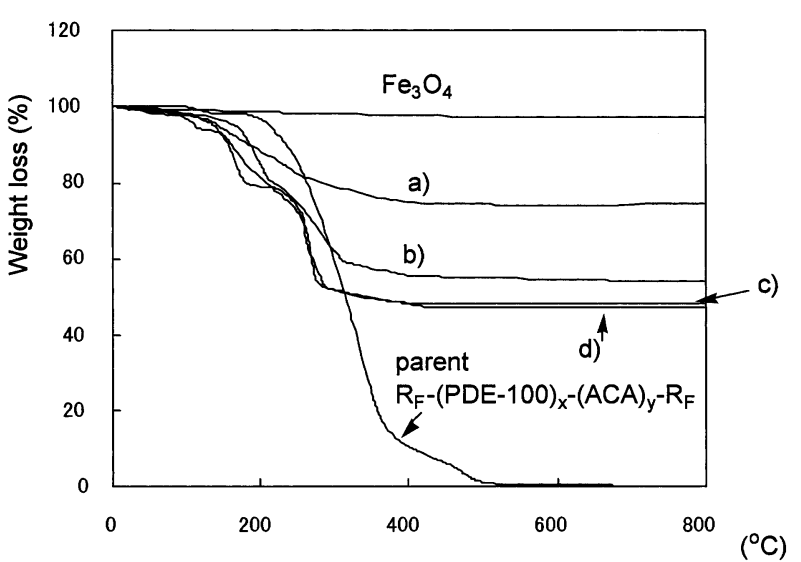

Fig. 4 Thermogravimeteric Analyses of $\mathrm{R}_{\mathrm{F}}-(\mathrm{PDE}-100)_{\mathrm{x}}-$ (ACA) $)_{y}-R_{F}-$ Magnetic Nanoparticles.

a) Run 3 in Table 2: content of $\mathrm{R}_{\mathrm{F}}-(\mathrm{PDE}-100)_{\mathrm{X}}-$ (ACA) $)_{y}-R_{F}$ by TGA: $23 \%$

b) Run 2 in Table 2: content of $\mathrm{R}_{\mathrm{F}}-(\mathrm{PDE}-100)_{\mathrm{x}}-$ (ACA) $)_{y}-R_{F}$ by TGA: $43 \%$

c) Run 1 in Table 2: content of $\mathrm{R}_{\mathrm{F}}-(\mathrm{PDE}-100)_{\mathrm{x}}-$ (ACA) y $_{\mathrm{F}}$ by TGA: $49 \%$

d) Run 4 in Table 2: content of $\mathrm{R}_{\mathrm{F}}-(\mathrm{PDE}-100)_{\mathrm{x}}-$ (ACA) $)_{y}-R_{F}$ by TGA: $50 \%$

of the TGA data in Fig. 4.

Interestingly, our present fluorinated magnetite nanocomposites were found to exhibit a good dispersibility and stability in tetrahydrofuran. To investigate the magnetic response against an external magnetic field, UV-vis. spectra were measured as a function of time after the permanent magnet was applied from the bottom of the cell (Fig. 5).

As shown in Fig. 5, fluorinated magnetite nanocomposites (No. 4 in Table 2) were shown to exhibit a good dispersibility and stability in tetrahydrofuran; however the absorbance extremely decreased in tetrahydrofuran by applying the magnet (a) in Fig. 5). This finding indicates that the fluorinated magnetite nanoparticles still maintain their ferromagnetism.

In this way, our present fluorinated magnetite nanocomposites have a good dispersibility and stability in organic media such as tetrahydrofuran. Thus, these fluorinated magnetite nanocomposites should be applicable to the surface modification of common organic polymers such as PMMA. In fact, we have succeeded in preparing the modified PMMA film $(254 \mu \mathrm{m})$ treated with $\mathrm{R}_{\mathrm{F}}-(\mathrm{PDE}-100)_{\mathrm{x}}$ (ACA) $)_{\mathrm{y}}-\mathrm{R}_{\mathrm{F}}$-magnetite nanocomposites ( $3 \mathrm{wt} \%$ based on the used PMMA). The contact angles of dodecane on the surface and reverse sides of this modified PMMA film are 12 and 0 degrees, respectively. A higher value for the contact angle on the surface side suggests that fluorinated magnetite nanocomposites could be arranged on the polymer 


\section{H. Yoshioka, T. Narumi and H. Sawada}

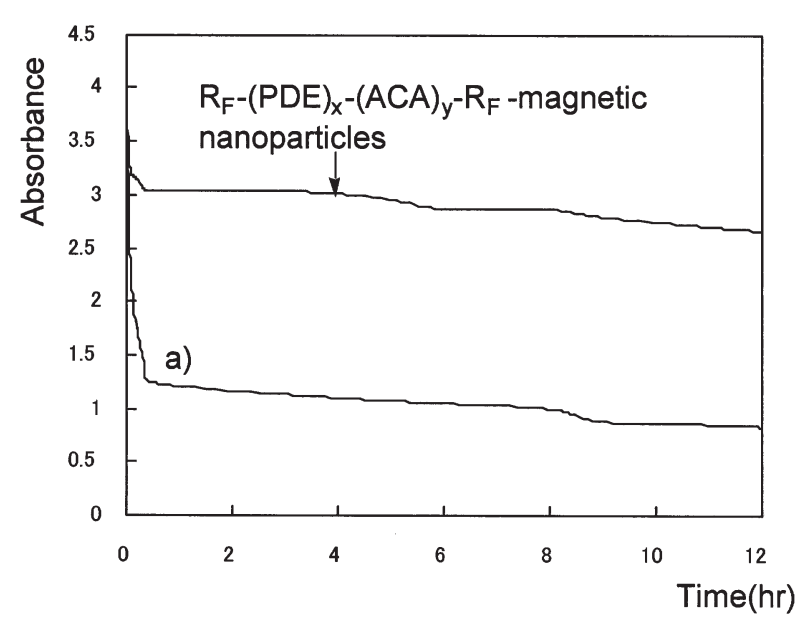

Fig. 5 UV-Vis Spectral Changes of the Absorption at $\lambda$ : $500 \mathrm{~nm}$ of THF Solutions in the Presence of $\mathrm{R}_{\mathrm{F}}{ }^{-}$ $(\mathrm{PDE})_{\mathrm{x}}-(\mathrm{ACA})_{\mathrm{y}}-\mathrm{R}_{\mathrm{F}}$-Magnetic Nanoparticles (Run 4 in Table 2) as a Function of Time $30^{\circ} \mathrm{C}$.

a) Absorbance from placing the magnet at the bottom of cell.

surface to exhibit a strong oleophobicity imparted by fluoroalkyl segments on the surface. This modified PMMA film was also found to exhibit magnetic behavior toward a permanent magnet.

In conclusion, it was verified that fluoroalkanoyl peroxide is a useful tool for the preparation of cross-linked fluorinated cooligomeric nanoparticles. These cross-linked fluorinated nanoparticles thus obtained were found to exhibit a good dispersibility and stability in water and a variety of organic media including fluorinated aliphatic solvents. These fluorinated nanoparticles were applied to the preparation of colloidal stable fluorinated nanoparticlesmagnetite nanocomposites in aqueous and organic media. These fluorinated magnetite nanocomposites were applied to the surface modification of traditional organic polymers such as PMMA to exhibit a good oleophobicity imparted by fluorine in the nanocomposites on their surface. Therefore, these fluorinated nanoparticles and fluorinated magnetic nanocomposites are expected to be widely applicable in a variety of fields as new attractive fluorinated nanocomposites. Further studies are actively in progress.

\section{ACKNOWLEDGEMENT}

Thanks are due to Asahi Glass Co., Ltd. and Toda Kogyo Corp. for supply of perfluoro-oxaalkanoyl fluorides and magnetite nanoparticles, respectively.

\section{References}

1. Johns, K.; Stead, G. Fluoroproducts-The Extremophiles. J. Fluorine Chem. 104, 5 (2000).

2. Ameduri, B.; Boutevin, B. Copolymerization of fluorinated monomers: Recent developments and future trends. J. Fluorine Chem. 104, 53 (2000).

3. Berret, J.-F.; Calvet, D.; Collet, A.; Viguier, M. Fluorocarbon associative polymers. Curr. Opinion Colloid Interface Sci. 8, 296 (2003).

4. Kujawa, P.; Goh, C.C.E.; Calvet, D.; Winnik, F.M. Do fluorocarbon, hydrocarbon, and polycyclic aromatic groups intermingle? Solution properties of pyrenelabeled bis(fluorocarbon/hydrocarbon)-modified poly(N-isopropylacrylamide). Macromolecules. 34, 6387 (2001).

5. Imae, T. Fluorinated polymers. Curr. Opinion Colloid Interface Sci. 8, 307 (2003).

6. Caminade, A.-M.; Turrin, C.-O.; Sutra, P.; Majoral, J.-P. Fluorinated dendrimers. Curr. Opinion Colloid Interface Sci. 8, 282 (2003).

7. Sawada, H.; Kawase, T. Synthesis of fluoroalkyl endcapped oligomers with fluoroalkanoyl peroxides-architecture of self-assembled aggregates of these oligomers. Kobunshi Ronbunshu. 58, 147 (2001).

8. Sawada, H.; Kawase, T. Properties of self-assembled aggregates of fluoroalkyl end-capped oligomers. Koubunshi Ronbunshu. 58, 255 (2001).

9. Sawada, H. Novel self-assembled molecular aggregates formed by fluoroalkyl end-capped oligomers and their application. J. Fluorine Chem. 121, 111 (2003).

10. Sawada, H.; Kawase, T. Architecture and applications of novel molecular assemblies imparted by the aggregations of fluoroalkyl segments. Yukigoseikagakukyokaishi. 57, 291 (1999).

11. Ameduri, B.; Boutevin, B. Well-architectured fluoropolymers: Synthesis, properties and applications Elsevier, Amsterdam, pp.231-348 (2004).

12. Sawada, H.; Iidzuka, J.; Maekawa, T.; Takahashi, R.; Kawase, T.; Oharu, K.; Nakagawa, H.; Ohira, K. Solubilization of fullerene into water with fluoroalkyl endcapped amphiphilic oligomers - Novel fluorescence properties. J. Colloid Interface Sci. 263, 1 (2003).

13. Sawada, H.; Iidzuka, J.; Kawase, T.; Oharu, K.; Nakagawa, H. Arrangement of fullerene above the poly(methyl methacrylate) surface with fluoroalkyl end-capped N-(1,1-dimethyl-3-oxobutyl)acrylamide polymers. Eur. Polym. J. 39, 1991 (2003).

14. Sawada, H.; Shindo, K.; Iidzuka, J.; Ueno, K.; Hamazaki, K. Solubilization and applications of single-walled carbon nanotubes into aqueous and organic media by the use of nanometer size-controlled fluoroalkyl endcapped oligomeric aggregates. Eur. Polym. J. 41, 2232 (2005).

15. Sawada, H.; Shindo, K.; Ueno, K.; Hamazaki, K. Reac- 
tions of fluoroalkanoyl peroxides with single-walled carbon nanotubes: Application to sidewall modification of single-walled carbon nanotubes with the Introduction of fluoroalkyl groups. Polym. Adv. Technol. 16, 764 (2005).

16. Sawada, H.; Ikeno, K.; Kawase, T. Synthesis of amphiphilic fluoroalkoxyl end-capped cooligomers containing oxime-blocked isocyanato segments: Architecture and applications of new self-assembled fluorinated molecular aggregates. Macromolecules. 35, 4306 (2002).

17. Sawada, H. Fluorinated peroxides. Chem. Rev. 36, 1779 (1996).

18. Sawada, H. Chemistry of fluoroalkanoyl peroxides, 1980-1998. J. Fliorine Chem. 105, 219 (2000).

19. Millan, A.; Palacio, F. Magnetic nanocomposites from nitrogen base polymer. Appl. Organomet. Chem. 15, 396 (2001).

20. Karis, T.E. An overview of rheology in the computer industry. J. Appl. Polym. Sci. 59, 1405 (1996).

21. Djokovic, V; Nedeljkovic, J.M. Stress relaxation in hematite nanoparticles-polystyrene composites. Macromol. Rapid Commun. 21, 994 (2000).

22. Song, G.; Bo, J.; Guo, R. The characterization and property of polystyrene compounding of $\alpha-\mathrm{Fe}_{2} \mathrm{O}_{3}$ in the nano-scale. Colloid Polym. Sci. 282, 656 (2004).
23. Flesch, C.; Unterfinger, Y.; Lami, E.B.; Duguet, E.; Delaite, C.; Dumas, P. Poly (ethylene glycol) surface coated magnetic particles. Macromol. Rapid Commun. 26, 1494 (2005).

24. Sauzedde, F.; Elaissari, A.; Pichot, C. Hydrophilic magnetic polymer latexes. 2. Encapsulation of adsorbed iron oxide nanoparticles. Colloid Polym. Sci. 277, 1041 (1999).

25. Mak, S.-Y.; Chen, D.-H. Binding and sulfonation of poly (acrylic acid) on iron oxide nanoparticles: A novel, magnetic, strong acid cation nano-adsorbent. Macromol. Rapid Commun. 26, 1567 (2005).

26. Schmidt, A.M. The synthesis of magnetic core-shell nanoparticles by surface-initiated ring-opening polymerization of $\varepsilon$-caprolactone. Macromol. Rapid Commun. 26, 93 (2005).

27. Matsuno, R.; Yamamoto, K.; Otsuka, H.; Takahara, A. Polystyrene- and poly(3-vinylpyridine)-grafted magnetite nanoparticles prepared through surface-initiated nitroxide-mediated radical polymerization. Macromolecules. 37, 2203 (2004).

28. Liao, M.-H.; Wu, K.-Y.; Chen, D.-H. Fast removal of basic dyes by a novel magnetric nano-adsorbent. Chem. Lett. 32, 488 (2003). 